Keynote Address presented at the Tenth New Zealand Geothermal

Workshop, Auckland, New Zealand, November 2-4, 1988, and to be published in the Proceedings

Modeling of Geothermal Reservoirs: Fundamental Processes, Computer Simulation, and Field Applications

K. Pruess

September 1988
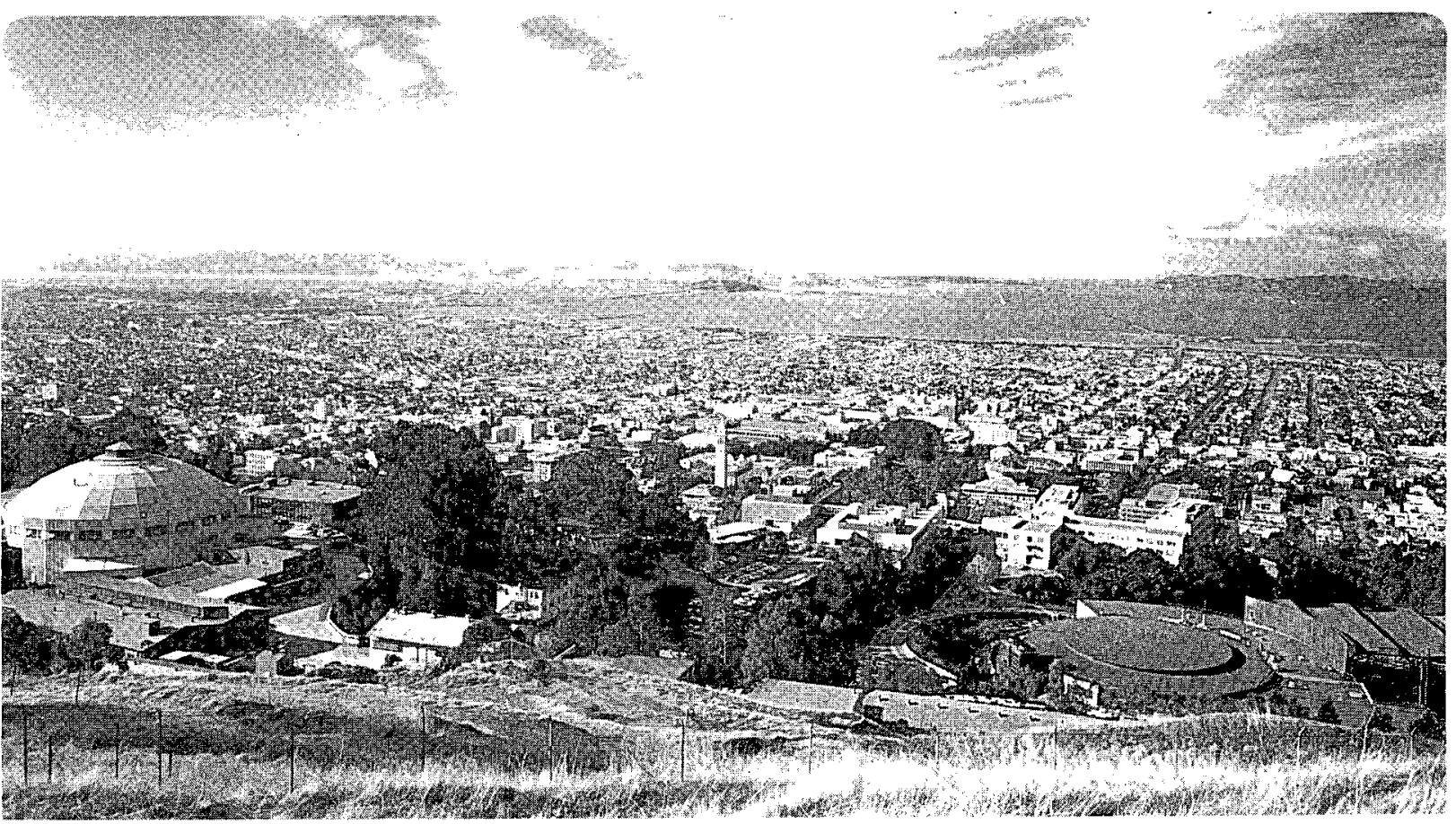

Prepared for the U.S. Department of Energy under Contract Number DE-AC03-76SF00098. 


\section{DISCLAIMER}

This report was prepared as an account of work sponsored by an agency of the United States Government. Neither the United States Government nor any agency Thereof, nor any of their employees, makes any warranty, express or implied, or assumes any legal liability or responsibility for the accuracy, completeness, or usefulness of any information, apparatus, product, or process disclosed, or represents that its use would not infringe privately owned rights. Reference herein to any specific commercial product, process, or service by trade name, trademark, manufacturer, or otherwise does not necessarily constitute or imply its endorsement, recommendation, or favoring by the United States Government or any agency thereof. The views and opinions of authors expressed herein do not necessarily state or reflect those of the United States Government or any agency thereof. 


\section{DISCLAIMER}

Portions of this document may be illegible in electronic image products. Images are produced from the best available original document. 


\begin{tabular}{|l|} 
DISCLAIMER \\
This document was prepared as an account of work sponsored \\
by the United States Government. Neither the United States \\
Government nor any agency thereof, nor The Regents of the \\
University of California, nor any of their employees, makes any \\
warranty, express or implied, or assumes any legal liability or \\
responsibility for the accuracy, completeness, or usefulness of \\
any information, apparatus, product, or process disclosed, or \\
represents that its use would not infringe privately owned rights. \\
Reference herein to any specific commercial products process, or \\
service by its trade name, trademark, manufacturer, or other- \\
wise, does not necessarily constitute or imply its endorsement, \\
recommendation, or favoring by the United States Government \\
or any agency thereof, or The Regents of the University of Cali- \\
fornia. The views and opinions of authors expressed herein do \\
not necessarily state or reflect those of the United States \\
Government or any agency thereof or The Regents of the \\
University of California and shall not be used for advertising or \\
product endorsement purposes.
\end{tabular}

Lawrence Berkeley Laboratory is an equal opportunity employer. 
LBL -25135

DE89 006662

\title{
Modeling of Geothermal Reservoirs: Fundamental Processes, Computer Simulation, and Field Applications
}

\author{
K. Pruess \\ Earth Sciences Division \\ Lawrence Berkeley Laboratory \\ 1 Cyclotron Road \\ Berkeley, California 94720 \\ USA
}

September 1988

\section{DISCLAIMER}

This report was prepared as an account of work sponsored by an agency of the United States Government. Neither the United States Government nor any agency thereof, nor any of their employees, makes any warranty, express or implied, or assumes any legal liability or responsibility for the accuracy, completeness, or usefulness of any information, apparatus, product, or process disclosed, or represents that its use would not infringe privately owned rights. Reference herein to any specific commercial product, process, or service by trade name, trademark, manufacturer, or otherwise does not necessarily constitute or imply its endorsement, recommendation, or favoring by the United States Government or any agency thereof. The views and opinions of authors expressed herein do not necessarily state or reflect those of the United States Government or any agency thereof. 


\title{
K. Pruess
}

\author{
Earth Sciences Division, Lawrence Berkeley Laboratory
} University of California, Berkeley, CA 94720

\begin{abstract}
This article ancmpts to critically evalunte the present state of the ant of geothermal reservoir simulation. Methodological aspects of geothermal reservoir modeling are briefly reviewed, with special emphasis on flow in fractured media. Then we examine applications of numerical simulation to studies of reservoir dynamics. well test design and analysis, and modeting of specific fields. Tangible impacts of reservoir simulation technology on geothermal energy development are pointed out. We conclude with considerations on possible future developments in the mathematical modeling of geothermal fields.
\end{abstract}

\section{INTRODUCTION}

Any scheme to harness the narural heal of the Earth for useful purposes is based on some kind of model about tho nature, distribution, and availability of a specific geochermal resource. Models are developed from qualitative and quantitativo information gathered during the exploration phase of a project, and they can take on different form, depending on the detail of available observational data, the nature of the questions posed by the project under consideration, and the personal or collective bias of the researcher(s). In its simplest form the model of a geothermal prospect may encompass litte more than some rough ideas about approximate depth and areal extent of the reservoir, and about reservoir temperature and permeability. As more data are assembled through geologic, geochemical, and geophysical observation, through exploratory drilling. and through well tests, it becomes possible to identify the thermal and hydrologic structure of the reservoir with more confidence and detril. Specific mathematical models can then be consuncted to evaluate and optimize geothermal utilization schemes. Mathematical models may range is complexity from a simple scounting of woel heas and fluid reserves, such as "stored heat" calculations, all the way to models which describe fluid and hen flow conditions in a geothermal field with greal spatial and tempord detail. based on a mathernatical description of the fundamental physical and chemical processes in the reservoir. Spatially derniled, of "dirtributed parameter" models, involve large amounts of numerical work. requiring special computer programs known as "reservoir simulators" for their construction.

Beginning in the early to mid-seventies. considerable effors were made to develop capabilities for computer simulation of the behavior of geochermal systems. The proponents of this development hoped that numerical reservoir simulators would improve our understanding of geothermal reservoirs, both in their natural state and in response 10 fluid production and injection. and would thereby contribute to more mpid and efficient resounce utilization. However, in the early days there was much skepticism in the geochermal community about the feasibility and potential benefits of reservoir simulation. Many people questioned whether a realistic and useful numerical simulation capsbility could in fact be achieved In addition, there were intense controversies about the proper muthematical and numerical methodologies to be used for describing fluid and heat flows with phase change effects. An important milestone in the development and acceptance of geothermal reservoir simulators was reached in 1980 when a code comparison project demonstrated satisfactory agreement between several simulation programs for a number of muiriphase fluid and heat flow problems (Stanford. 1980). Over the last ten years the field of geothermal reservoir simulation has matured considerably, and has developed from an esoleric and controversial subject into a technique widely applied in routine engineering practice.

An early review of geothermal reservoir simulation methodology and applications was given by Pinder (1979). Recent overviews of the field with extensive bibliography are those by O'Sullivan (1985) and Bodvarsson et al. (1986). The present article is not intended as a review, but as an atrempt to critically evaluate the state of the art of geothermal reservoir simulation. We discuss aspects of mathematical and numerical methods, as well as applications of these methods to the simulation of generic and "real" geothermal reservoirs, and of laboratory experiments. The two basic quescions that we are concerned with are: How "good" is the available simulation technology, i.e., what is it that our computer software tools are able to provide? And what have we learned from applications of the simulators, both in terms of improved understanding of geothermal reservoir dynamics, and in terms of improved engineering of geothermal energy projects?

\section{SMMULATION METHODOLOGY}

Earty work on numerical modeling of geothermal reservoirs emphasized the development of appropriate methodology. The basic physical processes goveming fluid and heat flow were clarified, and a mathematical description of these processes was developed The governing equations take the form of coupled partial differeatial or integral equations, which describe the variation of temperature, presture, and other thermodynamic parameters as functions of continuous space and time coordinates. For numerical solution the continuum equations need to be discretized. This has been secomplished with different approaches, including finite differences, integral finite differences, and finite elementa Discretiznion results in a set of nonlinear coupled algebraic equations, which can be solved by approximate linearization or by iterative procedures. Nonlinearities arising in phase change aro so severe that only iterative methods provide satisfactory solution. Whether approximate linearization or iteration is employed, most of the computational work done by a numerical simulator is expended in solving large systems of linear equations. Sundard lisear algebra methods have been employed in geothermal reservoir simulation, including direct solution and iterative matrix techniques.

We have developed a general-purpose reservoir simulator "MULKOM" which implements special techniques for effectively dealing with nonisothermal multiphase flow (Pruess, 1983, 1988). The basic governing equations solved by MULKOM describe mess and enersy conservation for mulricomponent fluids which in addition to water may contain a non-condensible gas such as $\mathrm{CO}_{2}$ and dissolved solids such as $\mathrm{NaCl}$ or $\mathrm{SiO}_{2}$. Fluid how is described with a multiphase extension of Darcy's law; in addition there can also be binary diffusion in the gas phase. Heat flow occun by conduction and convection, the latter including sensible as well as latent heat effects. Conversion of compressible wort ineo heat, and heat exchange berween fluids and rocks, are also modeled. The description of themodynamic conditions is based on the assumption of local thermodynamic equilibrium among all phases (liquid, vapor, solid). Fluid properties are 
represented by steam table equations for water, and by suitable empirical correlations for other constituents. Different components $\left(\mathrm{H}_{2} \mathrm{O}, \mathrm{CO}_{2}, \mathrm{SiO}_{2}, \ldots\right)$ can be present in several phases, according to local phase equilibria or by way of kinetic rates. Special techniques are used to handle phase transitions. All thermophysical and hydrologic parameters (including porosity and permeability) which appear in the goveming equations can be arbitrary (nonlinear and differentiable) functions of the primary thermodynamic variables.

In the early days of geothermal reservoir simulation many different approaches were pursued by different investigators (Pinder, 1979). However, over time there seems to have occurred a general convergence of methods, and the simulators presendy in use share most of the basic characteristics. We feel that at the time of this writing issues of simulation methodology have been largely settled. A number of reservoir simulation codes are available in the public domain as well as from private vendors. which can handle highly nonlinear fluid and heat flow processes, including phase transitions, in a robust and stable manner. The accuracy of these codes has been temonstruted by comparison with analytical solutions, as well as by applications to laboratory and field data. Limitations still exist in modeling chemically and mechanically coupled processes, in which formation porosities and permeabilities can vary in response to mineral dissolution and precipitation, and changes in pore pressure and rock stress. Also there is a lack of empirical data on multiphase flow properties of real rough-walled fractures. Further work is needed to improve our ability to model sharp phase and concentration fronts.

For completeness it should be mentioned that numerical reservoir simulacion is widely used in the oil and gas industry, and in the management of groundwater resources (Peaceman, 1977; Axiz and Sertari, 1979). Geothermal reservoir simulation borrows heavily from concepts and methods developed in these fields.

\section{APPROACHES FOR SIMULATING FLOW IN FRACTURED MEDIA}

Sorne special problems are posed by the fect that most geothermal reservoirs oecur in frectured formations with low rock matrix permeability. The frectures provide moss of the reservoir permeability. while most of the fluid and heas reserves are stored in the marrix. From a conceptual viewpoint the simpless approach for modeling flow in frectured media is to explicitly include fractures in the flow domain by means of suitably chosen small volume elements (grid blocks). Because of the amount of geometric detail involved in this appronch, is can oaly deal with highly idealized problems with very few fractures and a high degree of symmery. At the oppoaize extreme compered to the "explicil frectures" approsech is the "effective conainuum" lechnique (Pruess et al., 1985a). This approsch involves the drastic simplification of noe making any geometric represenution of the fractures at all: instead their flow effects are approximated by means of suitably modified hydrologic parameters, chiefly relative permeability curves. Thereby the numerical problem is reduced to that of a porous medium model; however, such a "porous medium" or "effective continuum" approximntion can only be justified when marix and fractures remain in approximate thermodynamic equilibrium locally at all times (Pruess et 31., 1988).

For geochermal reservoirs with spacing between major fractures often as large as several tens of meters, the thermodynamic equilibration between matrix and fractures in response to chang. ing conditions in the fractures (caused by fluid withdrawal or nonisothermal reinjection) is alow process. Indeed, thermal diffusivity of rocks is typically of the onder of $10^{6} \mathrm{~m}^{2} / \mathrm{h}$, so the penetration of conductive effects inwo matrix blocks with linear dimension of $30 \mathrm{~m}$ will require approximucely 30 year. As far as fluid flow is concemed the permesbility contrast berween frectures and matrix is typically of the onder of $10^{4}$ (10 millidarcy versus 1 microdarcy); the corresponding contrass in hydraulic diffusivities is even larger because of small fracture porosity. Thus, reservoir perturbations induced by production or injection operations will propagate through the fracture system typically more than 100 times faster than through the rock matrix. These considerations indicate that one should expect persistent nonequilibrium conditions between matrix and fractures in many fractured geothermal reservoirs during exploitation. An effective continuum approximation should be applicable only when fracture spacing is "sufficiently" small. For conductive equilibration with impermeable blocks to occur within a few months, fracture spacing must be less than $2.3 \mathrm{~m}$. If one wishes to resolve changes in reservoir condicions on a spatial scale of $50 \mathrm{~m}$, say, then an effective continuum approximation should be applicable only when fracture spacing is less than $1 \mathrm{~m}$. These numbers are meant to give an onder-of-magnitude estimate for the fracture spacing required to justify application of the effective continuum approach.

Persistent nonequilibrium conditions berween matrix and fractures, and the accompanying transient interporosity flow effects can be modeled with the method of "multiple interacting continua" (MINC; Pruess and Narasimhan, 1982, 1985). An extension of the well known double-porosity method (see Figure 1; Barenblatt et al., 1960; Warren and Root, 1963), the MINC method combines feanures of both the explicit fracture and effective continuum approaches. The fracture system is modeled as a continuum, which interacts with several matrix continua. The latter are defined based on the following consideration. Due to vastly different diffusivities, exploitation-induced perturbations in thermodynamic conditions in a fractured reservoir will propagate rapidly through the network of interconnected fractures, while invading the matrix blocks only slowly. Responding to the changing conditions in the fractures, the thermodynamic conditions in the marix blocks will then change in a way that is primarily controlled by the distance to the nearest fracture. This concept leads to a discretization of matrix blocks into a series of nested volume elements, as schematically shown in Figure 2. Flow in this system can easily be modeled by means of the integral finite difference rechnique. which only requires specification of grid block volumes, interface areas, and nodal distances (Pruess, 1983a). The concept of discretizing matrix blocks sccording to distance from the nearest fracture can also be applied to irregular and stochastic fracture discributions (Pruess and Karasaki, 1982). If only two continus (one for the fractures, one for the marix) are specifiec, the MINC method reduces to the double-porosity approach.

The accuracy of the MINC method has been demonstrated by comparison with analycical solutions (Lai et al., 1986), with explicit fracture calculations (Wu and Pruess, 1988), and with Inboratory experiments ( $\mathrm{Lam}$ et al., 1988). We have recently developed a simplification of the MINC method that is applicabie to the problem of heat exchange with impermeable matrix blocks (Pruess and $W_{1}, 1988$ ). The simplification obviates the need for subgridding of matrix blocks; instead, temperature in the blocks is represented by means of a simple trial function, as follows (Vinsome and Westerveld, 1980):

$$
T(x, t)-T_{i}=\left(T_{t}-T_{i}+p x+q x^{2}\right) \exp (-x / d)
$$

Hero $x$ is the distance from the block surface, $T_{i}$ is initial block temperanure, $T_{f}$ is the time-varying temperature in the fractures (at the block surface), $p$ and $q$ are time-varying fit parameters, and $d$ is the penetration depth for heat conduction, given by $d=\sqrt{(D i) / 2}$, where $D$ is the thermal diffusivity of the blocks. The parameters $p$ and $q$ are calculated at each time step of a simulacion run from requirements of energy conservation in the blocks. and continuity of heat flux at the block surface. This semi-eralytical approach to interporosity flow can give accurate results with no noticeable increase in computational effor compered to simple porous medium models. A completely analogous approach can bo used to calculate fluid exchange with permeable blocks in single-phase liquid reservoirs.

\section{APPLICATIONS}

Geothermal reservoir simulators have been used to model laboratory experiments. to study fundamental aspects of geothermal 


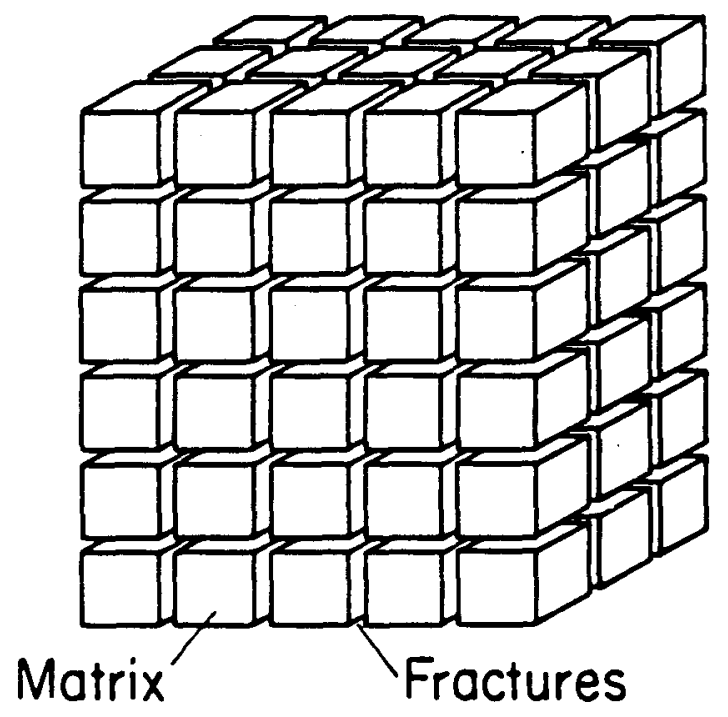

Figure 1. Idealized double-porosity model of a fractured porous medium.

reservoir dynamics, and to perform simulation studies for specific geothermal fields. Altrough only few applications to labornwery experiments have been made, theas are important for confirming the basic physics of fluid and heat flow incorporated into the simulators (Verme et al., 1985; Lam et al., 1988). The study of reservoir dynamics has been a fruitful application of numerical simulators (see Table 1), and has helped in developing a betur understanding of fluid and heat flow mechanisms in geothermal reservoirs. Baxic insights into the explointion of different kinds of geothermal systerms have been gained, and issves in well teat. ing of nonisothermal multiphase systems have been clarified.

From a practical viewpoint the mont interesting applications of reservoir simulator are for history matching and performance prediction of specific geochermal fields. A number of field case studies have been published (seo the recent reviews by O'Sulliven, 1985. and Bodvarsson et al., 1986), and a considerably larger number remains unpubliahed because of proprietury restrictions on the dan. We believe that the existing stodies have shown that it is indeed possible to build sufficiently quantuative and reliable models of geothermal fields to reproduce observed field behavior (history matching), and to be able to obtain useful guidance for field development and management.

Table 1. Advance in Reservoir Dymamia from Numerical Simulations

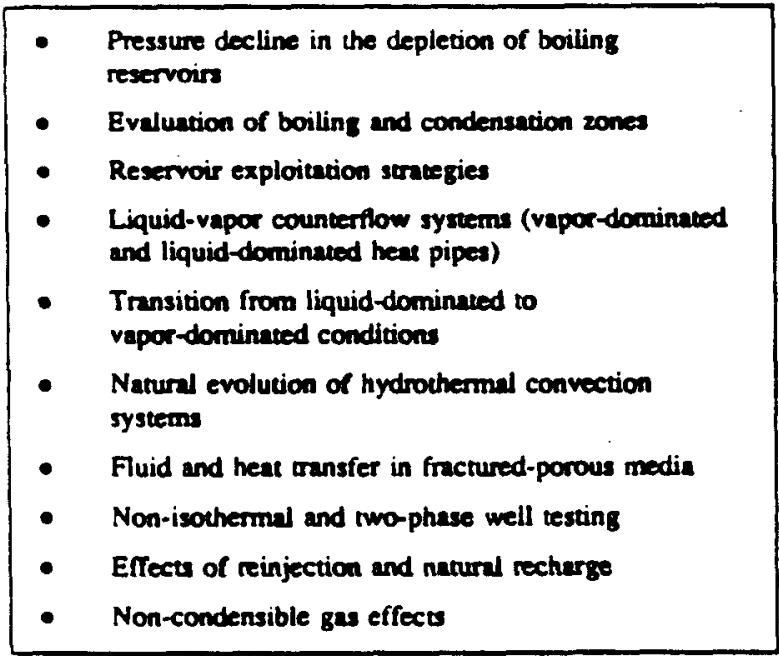

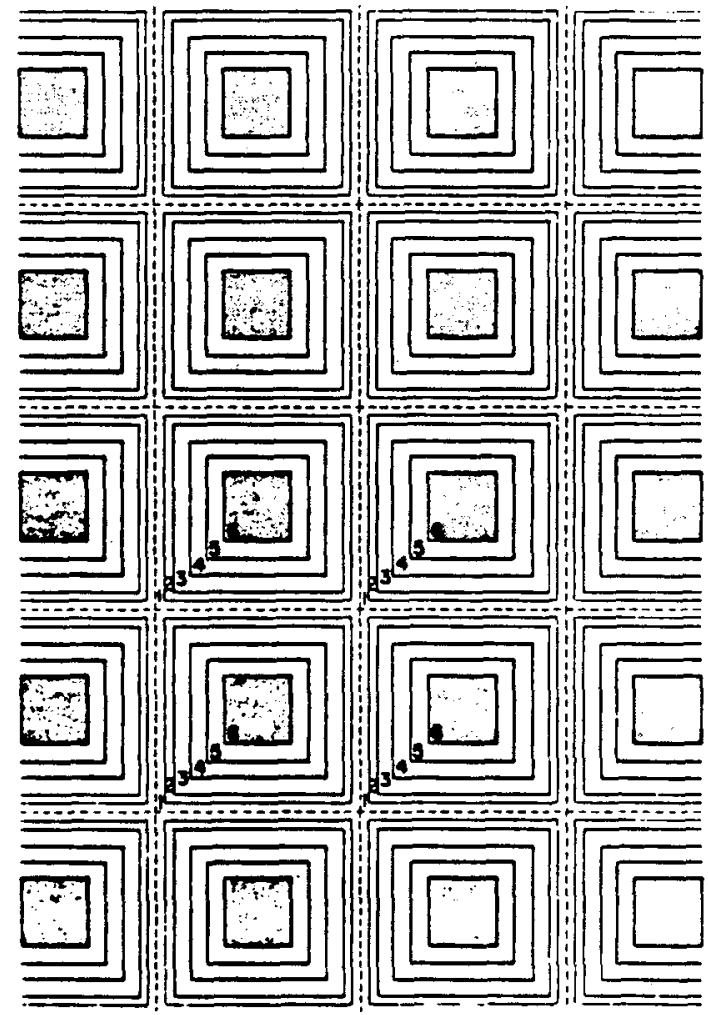

Figure 2.

Basic space discretization in the method of "multiple interacting continua" (MINC; after Pruess and Nerisimhan, 1982).

\section{RESERVOIR DYNAMICS}

The versatility of geothermal reservoir simulators has made possible applications to a wide range of fluid and heat flow problems. Table 1 lists the main aress in which numerical simulation studies have produced significant advances in our understanding of geothermal systems.

Applications of the MINC method have produced valuable insights ine fluid and heat flow conditions in fractured boiling rearvoirs. For exemple, mechanism of conductive enhancement of flowing enthalpy was discovered which will cause superheated steam to be discharged from matrix blocks of low permeability, even if liquid saturation in the matrix blocks is large (Pruess and Nansimtian, 1982: Pruess, 1983b). Possible mechunisme for natural evolution of two-phase liquid and vapor dominated sysuems were demonstrated (Pruess, 1985; Pruess et al. 1987). The presence of non-condensible gases was shown to give rise to some unusual effects in fractured media (Pruess et 1.. 1985b; Bodvarseon and Gaulke, 1987).

Of particular interese in fractured geothermal reservoirs is their response to reinjection of heat-depleted waste waters. This could result in enthanced energy recovery, but it also raises the possibility of premanure thermal breakthrough of reinjected waters along preferendial pachways (major fractures or faults). Tracer tests can reveal such short-circuiting paths, but there is no general quantiatively useful relacionship between breakthrough of tracer and thermal fronta Simulation sudies have suggested that thermal degredacion a production wells should be largely reversible if the offending injector is shut in (Pruess and Bodvarsson, 1984). Injection studies in fractured rwo-phase and vapor zones have shown interesting fluid and heat flow phenomena (Pruess, 1983b; Pruess and Narnsimhan, 1985; Bodvarsson et al., 1985; Calore et a.. 1986). In a five-spot production-injection problem it was found that for $50 \mathrm{~m}$ fracture spacing a nearly complete heat sweep could be achieved, while for $250 \mathrm{~m}$ fracture spacing 
significant heat reserves were bypassed. This can be scen from Figure 3, which shows the simulated temperature profile in the fractures along a line connecting production and injection wells after 36.5 years of constant-rate production and $100 \%$ reinjection (Pruess and $W u, 1988$ ). The data for $50 \mathrm{~m}$ fracture spacing virtually coincide with a porous medium model, indicating excellent thermal sweep, while those for $250 \mathrm{~m}$ fracture spacing indicate substantial bypassing. Figure 3 also shows excellent agree. ment between results obtained from the semi-analytical method for interporosity flow and the MINC method.

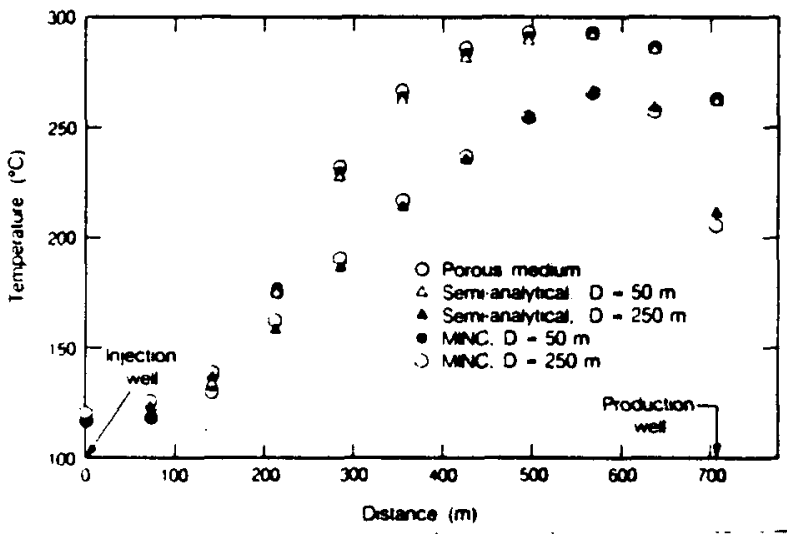

Figure 3. Simulated temperature profiles in five-spot production-injection system for different fracture spacings after 36.5 years (after Pruess and $W_{u}$, 1988)

\section{WELL TESTING}

Another practically important area in which much progress has been made through applications of numerical simulators is in the design and analysis of well tests in nonisothermal and two-phase systerns. Interpretution of such tests is made difficult by highly variable fluid properies and nonlinear flow effects. Numerical simulation has provided a convenient and flexible tool for generating test cases that could then be used to evaluate the applicability of analysis techniques borrowed from isothermal singlophase flow. Grant (1978), Garg (1980), Grant and Sorey (1979), and Sorey ef l. (1980) showed that under certuin conditions pressure unnsients resulting from constent-rate production from iwo-phase zones can be approximately described with a linear diffusion equation. O'Sullivan and Pruess (1980), Schroeder et al. (1982), Benson and Bodvarsson (1982), and Bodvarseon et al. (1984) examined nonisothermal injection tests and found that semi-log analysis besed on the line source solution was applicable to porous medium systems. Garg and Pritchen (1988) used numerical simulation to examine pressure interference tests in single-phase reservoirs that evolve a rwo-phase zone in response to fluid production. Simulation of nonisothermal well tests in fractured single- and two-phase reservoirs have shown very compiex behavior that appears to defy simple analysis methods (see O'Sullivan. 1987, and references therein). Figure 4 shows simulated pressure buildups in response to constunt-rate injection of water with an enchalpy of $500 \mathrm{~kJ} / \mathrm{kg}$ (corresponding to approximately $120^{\circ} \mathrm{C}$ ) into a fractured reservoir with single-phase liquid at an initial temperature of $240^{\circ} \mathrm{C}$ Marix blocks se assumed to be cubes of $10 \mathrm{~m}$ side length. The buildup for permeable blocks displays varying curvanure with no straight-line segmente. Agreement between results obtained from a semi-analytical representation of incerporosity flow and the MINC method is excellent. Additional complications arise in fractured media from the common presence of several well feeds at different temperalures. This can give rise to large and persistent internal wellbore flows with strong pressure effects which, if not recognized as such, would lead one to draw erroneous conclusions on formation properties (Grant et al., 1982; Ripperda and Bodvarsson, 1988). Large pressure effects can also occur from vertical upflow of steam in response to saturation changes near producing wells (Bodvarsson et al., 1987).

It appears that much work remains to be done in the interpretation and analysis of nonisothermal and two-phase well tests, and that numerical simulation will continue to serve as the premier investigative tool in these studies.

\section{FIELD STUDIES}

A number of simulation studies for specific geothermal fields have appeared in the open literature (see the reviews by O'Sullivan, 1985; Bodvarsson et al., 1986). A considerably larger number of studies remains proprietary in the files of engineering consulting firms and geothermal operators. In the present paper we will not attempt to review specific case studies; rather we wish to discuss some general issues that arise in the application of numerical reservoir simulators to geothermal fields.

Simulators are constructed on the basis of sound physical laws of fluid and heat flow, and employ sophisticated mathematical and numerical techniques to quantify these phenomena. The process of numerical reservoir simulation, however, is a much more subjective and uncertain endeavour. The starting point is a concepcual model of the field, which is arrived at in a highly intuitive manner by integrating the ideas of the diverse specialists that participate in field exploration and development. Depending upon the most significant field development issues at hand, simulation models of different degree of detail and comprehensiveness can then be constructed. In order to be able to make credible predictions of reservoir response to exploitation it is important that proper initial conditions be used. The issue of initial conditions is especially important in two-phase reservoirs, where large pressure and enthalpy effects can result from the initial distribution of liquid and vapor phases which usually is highly uncertain. Consistent initial conditions can be obtained from careful modeling of the natural state, including upflow and discharge zones, surface manifestations, and trends in chemical composition of the geofluids. Natural state modeling entails a very considerable effort, which in practice is often shoncut under pressure from more immediate problems arising in field development.

Typical questions which numerical simulation may be called upon to answer relate to (i) the generating capacity of a field. (ii) future nees, enthalpies, and chemical composition of well discharges, (iii) identification of drilling targets, (iv) optimal well spacings and completions, and (v) design and impact of reinjection of heat-depleted fluids. Most reservoir engineers would agree with the proposition that a reliable prediction of reservoir performance could be achieved if only sufficiently detailed and reliable data on the thermodynamic and hydrologic structure of a

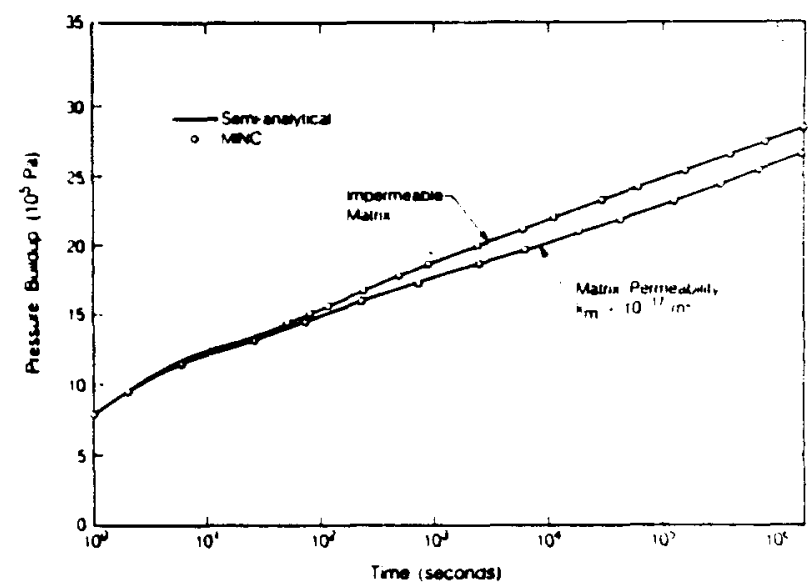

Figure 4. Simulated pressure buildups for non-isothermal injoction into a fractured reservoir. 
geothermal field were available. However, in practice field data have been a notorious bottleneck that limits the reliability of simulation predictions. The reservoir engineer invariably must work with incomplete data of usually uncertain accuracy. Numerical simulation then becomes an often redious trial-anderror process, in which rough estimates or guesses must be substituted where sufficiently detailed data are unavailable; these guesses must be refined until an acceptable agreement is found between simulated and observed reservoir behavior. Numerical fluid and heat flow models usually are not unique, and must be further constrained from geochemical, geologic, and geophysical data.

Applications of numerical simulacons to specific fields can vary greatly in scope. At its simplest, simulation studies would be undertaken to address very specific issues, such as optimal well spacing. or the adequacy of a proposed reservoir mechanism to explain certain observed features. This sort of study can be done with schematic idealized models that only need to capture those reservoir features that are pertinent to the specific problem at hand At its most ambitious, simulation models would attempt to be "all-encompassing," including a detailed three-dimensional representation of all significant hydrogeological features, and attempting to predict future deliverabilities of all wells individually in quanticative detail. The main value of the latter kind of modeling approach may perhaps not be found in the detailed predictive ability, which is questionable given the various uncertainties on different space and time scales, but in the push towands integrating the views of the different disciplines (geology. geophysics. geochemisury, reservoir engineering) into a single coherent model of the field. This integration of expertise may juse lead to a better understanding of the field and to betrer engineering decisions. It may also enhance the confidence of investors in the feasibility of a proposed geothermal project.

\section{DISCUSSION AND CONCLUSIONS}

A pervasive feature of geothermal reservoir evaluation is uncertainty. Our ability to characterize geothermal reservoirs, of any subsurface flow jystem, is and always will be limited. Predictions based on incomplete data of unknown accuracy cannor be more reliable than the dat themselves Numerical simulation can not provide any magic to fundamentully change these facts, but it can provide tool to augment and supplement other approsches. For example. effects of uncertain reservoir conditions and parameters can be quickly and easily examined by means of sensitivity studies. Likewise, the pros and cons of alternative field development plans can be exploned.

We believe thas numerical reservoir simulation sondies have made tangible impacts on geothermal energy developinent. Such studies have improved our understanding of fluid and heat flow dynamics in different types of geothermal systems. Important insights were gained into the design and andysis of well tests under nonisothermal and two-phase conditions. Simulation soudies of production-reinjection systems with premature thermal breakthrough along major faults or fractures have dispelled some fears regarding reinjection. They indicated that, while such breakthroughs may not be entirely avoidable based on unacer data. they would be limited and largely reversible if the offending injector is shut in.

As far as the development of specific geothermal fields is concerned. an example of tangible impacts is provided by the soudies underaken for the Olkaria geothermal field, Kenya. An early study (Bodvarsson et al. 1982) indicated the desirsbility of completing wells in the deep liquid-dominated zone rather than in the shallow steam zone, because the former would permit a more unifom depievion of mass and beat reserves. More recently, Bodvarsson et at. (1987) demonsurated thas an efficient long-term depletion of Olkaria could be sccomplished with significantly lower well density than had previously been used in the development of the field. There are undoubiedly many more examples of tangible impacts on geothermal field development among the many simulation studies that have not been released to the public.
With geothermal reservoir simulation software and services in routine commercial use, it is of interest to speculate on future trends and possibilities in this field. Where is a need and a potential for major improvements in our simulation tools and their use? What are the possibilities and benefits for realizing improvements near-term as well as long-term?

Generally speaking, it would be desirable for simulators to become more realistic and comprehensive in their representation of physical and chemical processes in geothermal reservoirs. At the same time execution speed and case of use should be improved.

Table 2 lints number of specific items that should be considered for mapping out future research directions. Some fundamental reservoir processes require better definition. An example is multiphase flow in fractures, which is the dominant production mechanism in most high-temperature geothermal fields. Yet next to nothing is known about two-phase flow in "real" roughwalled frectures; an effort to develop laboratory experiments in this area has been iniciated at LBL to supply some of the basic information needed. The coupling of chemical and mechanical processes to hydrology is not usually included in geothermal reservoir simulators, and geochemical and geophysical data are not usually input into or predicted from fluid and heat flow simulations (second point in Table 2). A broadened scope, possibly also including flow in wellbores and surface lines, could lead to more comprehensive and realistic reservoir models. Another area of possible improvement is in the mathematical and numerical rechniques. Most of the numerical work in reservoir simulation is

Table 2. Poedible future improvements in geothermal reservoir simulation technology

(1) Bether definition and more complete description of reservoir processes

(2) Broadened scope (geochemistry, geophysics)

(3) Improved mathematical and numerical techniques

(4) Better user interface/data handling

(5) Application of expert system concepts (artificial intelligence)

(6) More complete and reliable field data

7) Better application methodology through broader track recond

expended in the solution of large systems of linear equations. Efficiency gains in this area could make it possible to improve the geometric definition and realism of simulations, especially for three-dimensional problems. Furthemore, more chemical species could be included in flow models. Improved capabilities for tracking shap phase or composition fronts are also desirable.

A reservoir simulation effort involves working with large amounis of dan which is a tedious and time consuming process. One could expect that substantial gains in efficiency may be possible from appropriate interactive and graphic techniques. The fifth point in Table 2, expent systems. relates to both broadened scope and better user interface. In the development of a simulation model of a geothermal field the reservoir engineer attempts to incegrate and synthesize large amounts of information from different scientific and engineering disciplines. Help and advice from geologists. geochemists, and geophysicists is needed in this task. Expen systems could offer a way to make such multidisciplinary advice available at a desktop cerminal in a convenient and efficient way.

The critical imporance of field datn (point 6) has already been pointed out. The final point in Table 2 suggests to continue building a uack recond of publicly available simulation studies, to improve our understanding of how to best use reservoir simulators and the results from them. 


\section{ACKNOWLEDGMENT}

The author would like to thank Marcelo Lippmann and Sally Benson for their review of the manuscript and helpful discussions. This work was supported by the U.S. Department of Energy, Geothermal Technology Division, under Contract No. DE-AC03-76SF00098.

\section{REFERENCES}

Aziz, K. and Settari, T., Petrolewn Reservoir Simulation, Applied Science Publishers, London, 1979.

Barenblatt, G. E., Zheltov, I. P. and Kochina, I. N., Basic Concepts in the Theory of Seepage of Homogeneous Liquids in Fractured Rocks. J. Appl. Math., (USSR), Vol. 24, No. 5. pp. 1286-1303, 1960.

Benson, S. M. and Bodvarsson. G. S., Nonisothermal Effects During Injection Tests, Paper SPE-11137, presented at the 57th Annual Technical Conference and Exhibition of the Society of Petroleum Engineers, New Orleans, LA, 1982

Bodvarsson, G. S., Benson, S. M., Sigurdsson. O., Stefansson, V. and Eliasson, E.T. The Krafla Geothermal Field. Iceland. 1. Analysis of Well Test Dara, Warer Resowr. Res., Vol. 20. No. 11, pp. 1515-1530, 1984.

Bodvarsson. G. S., Cox, B. L. and Rippends, M. Effects of Steam-Liquid Counterflow on Pressure Transient Dan From Two-Phase Geothermal Reservoirs, paper SPE-16775, presented at the 62nd Annual Technical Conference and Exhibition of the SPE. Dallas, TX. September 1987.

Bodvarsson, G. S. and Gaulke, S., Effects of Noncondensible Gases on Fluid Recovery in Fractured Geothermal Reservoirs, SPE Reservoir Engineering, pp. 335-342, August 1987.

Bodvarsson, G. S. Pruess, K., Lippmann. M. J. and Bjbrnsson, S., Improved Energy Recovery from Geohermal Reservoirs. J. Pet. Tech., Vol. 34, No. 9, pp. 1920-1928, Septernber 1982.

Bodvarsson, G. S., Pruess, K. and O'Sullivan, M. J., Injection and Energy Recovery in Frnctured Geochermal Reservoirs Soc. Pet. Engr. J.. Vol. 25. No. 2. pp.303-312. April 1985.

Bodvarsson, G. S., Pruess, K. and Lippmann, M. J., Modeling of Geothermal Systems, J. Pet. Tech., Vol. 38, No. 10, pp. 1007-1021, September 1986.

Bodvarsson, G. S., Pruess, K. Stefansson, V., Bjormsson, S. and Ojiambo, S. B., East Olkaria Geochermal Field, Kenye 2 Predictions of Well Performance and Reservoir Depletion, J. of Geophys. Res., Vol. 92. No. B1. pp. 541-554, 1987.

Calore, C., Pruess, K. and Celati, R., Modeling Studies of Cold Water Injection Into Fluid-Depleted. Vapor-Dominated Geothermal Reservoirs, paper presented at Ilth Workshop Geothermal Reservoir Engineering. Stanford University. Stanford. CA, January 1986.

Garg. S. K., Pressure Transient Analysis for Two-Phase (WaterSteam) Geothermal Reservoirs, Soc. Per. Engr. J., Vol. 20 , pp. 206-214, 1980.

Garg. S. K. and Pritchet, J. W.. Pressure Interference Dala Analysis for Two-Phase (Water/Steam) Geochermal Reser voirs, Waser Resour. Res., Vol. 24, No. 6, pp. 843-852, 1988.
Grant, M. A., Two-Phase Linear Geothermal Pressure Transients: A Comparison With Single-Phase Transients, N. Z. J. Sci. Vol. 21, pp. 355-364, 1978.

Grant, M. A., Donaldson, I. G. and Bixley, P. F., Geothermal Reservoir Engineering, Academic Press, New York, 1982.

Grant, M. A. and Sorey, M. L. The Compressibility and Hydraulic Diffusivity of Water-Steam Flow, Water Resour. Res., Vol 15, pp. 684-686, 1979.

Lai, C. H., Pruess, K. and Bodvarsson, G. S., On the Accuracy of the MINC Approximation, Lawrence Berkeley Laboratory Report LBL-21025, Berkeley, CA, February 1986.

Lam. S. T., Hunsbedh A., Kruger, P. and Pruess, K., Analysis of the Stanfond Geothermal Reservoir Model Experiments Using the LBL Reservoir Simulator, Geothermics, Vol. 17. No. 4, 1988, in press.

O'Sullivan, M. J., Geothermal Reservoir Simulation, Energy Research, Vol. 9, pp. 313-332, 1985.

O'Sullivan, M. J., Aspects of Geothermal Well Test Analysis in Fractured Reservoirs, Transport in Porous Media, Vol. 2. No. S, pp. 497-517, 1987.

O'Sullivan, M. J. and Pruess, K., Analysis of Injection Testing of Geothermal Reservoirs. Transactions, Geothermal Resources Council, Vol. 4, pp. 401-404, September 1980.

Peaceman, D. W., Fundamentals of Numerical Reservoir Simulaiion, Elsevier, Amsterdam 1977.

Pinder, G. F., State-of-the-Art Review of Geothermal Reservoir Modeling, Lawrence Berkeley Laboratory Report LBL9093. March 1979.

Pruess, X., GMINC-A Mesh Generator for Flow Simulations on Fractured Reservoirs., Lawrence Berkeley Laboratory Report LBL-15227. Berkeley. CA. March 1983a.

Pruess, K. Heat Transfer in Fractured Geothermal Reservoirs with Boiling. Warer Resowr. Res., Vol. 19, No. 1, pp. 201. 208, Feburry 1983b.

Pruess, K., Development of the General Purpose Simulator MULKOM. Annual Repon 1982. Earh Sciences Division, repon LBL-15500, Lawrence Berkeley Laboratory, 1983.

Pruess, K. A Quantitative Model of Vapor Dominated Geothermal Reservoirs as Heat Pipes in Fractured Porous Rock. Transactions, Geothermal Resources Council, Vol. 9, Part II. pp. 353-361, August 1985.

Pruess, K. SHAFT, MULKOM. TOUGH: A Set of Numerical Simulators for Multiphase Fluid and Heat Flow, Geotermia, Rev. Mex Geoenergia, Vol. 4, No. 1, pp. 185-202. 1988 (also: Lawrence Berkeley Laboratory report LBL-24430).

Pruess, K. and Bodvarsson, G. S., Thermal Effects of Reinjection in Geothermal Reservoirs With Major Vertical Fractures, $J$. Pet. Tech., Vol. 36, No. 10. pp. 1567-1578, Sepiember 1984.

Pruess, K., Celati, R., Calore, C. and D'Amore, F., $\mathrm{CO}_{2}$ Trends in the Depletion of the Landerello Vapor-Dominated Reservoir. Lawrence Berkeley Laboratory report LBL-19092. presented at Tenth Workshop Geothermal Reservoir Engineering, Stanford University, Stanford, CA 1985b. 
Pruess, K., Celati, R., Calore, C. and Cappeti, G., On Fluid and Heat Flow in Deep Zones of Vapor-Dominated Geothermal Reservoirs, paper presented at Twelfth Annual Workshop Geothermal Reservoir Engineering, Stanford University, Stanford, CA, January 1987, also Lawrence Berkeley Laboratory report LBL-22810.

Pruess, K. and Karasaki, K., Proximity Functions for Modeling Fluid and Heat Flow in Reservoirs With Stochastic Fracture Discributions, paper presented at Eighth Workshop on Geothermal Reservoir Engineering, Stanford University, Stanford, CA, December 1982.

Pruess, K. and Narasimhan, T. N., On Fluid Reserves and the Production of Superheared Siean from Fractured, VaporDominated Geothermal Reservoirs, J. Geophys. Res., Vol. 87. No. Bt 1, pp. 9329-9339, 1982.

Pruess, K., and Narasimhan, T. N., A Practical Method for Modeling Fluid and Heat Flow in Fractured Porous Media, Soc. Pet. Engr. J., Vol. 25, No. 1, pp. 14-26, February 1985.

Pruess, K., Tsang, Y. W. and Wang, J. S. Y., Modeling of Strongly Heat Driven Flow in Partially Saturated Fractured Porous Media, International Association of Hydrologists (ed.), Memoires, Vol. XVII. pp. 486-497, 1985a

Pruess, K., Wang, J. S. Y. and Trang, Y. W., On Thermohydrologieal Conditions Near High-Level Nuclear Wastes Emplaced in Partially Saturated Fractured Tuff. Part 2. Effective Continuum Approximation. Submined to Waser Resour. Res., 1988.

Pruess, K. and Wu, Y. S., A Semi-Analytical Method for Heal Sweep Calculations in Fractured Reservoirs, paper presented at 13th Workshop on Geothermal Reservoir Engincering. Stanfond University, Januery 19-21, 1988, (LBL-24463).

Ripperda, M. and Bodvarsson, G. S., Andysis of Internal Wellbore Flow, paper presented a 13ih Workshop on Geothermal Reservoir Engineering. Stanford University, Stanfond, CA, January 1988.

Schroeder, R. C., O'Sullivan, M. J., Pruess, K., Celasi, R. and Ruffilli, C., Reinjection Studies of Vapor-Dominated Sys Iems, Geothermics, Vol. II, No. 2, pp. 93-120, 1982.

Sorey, M. L., Grant. M. A. and Bradford, E., Nonlinear Effects in Two-Phase Flow. To Wells in Geothermal Reservoiss. Waser Resow. Res., Vol. 16, No. 4, pp. 767.777, August 1980

Stanford Geothermal Program (ed.) Proceedings Special Panel on Geothermal Model Intercomparison Study, paper presented at Sixth Workshop on Geothermal Reservoir Engineering. Repon SGP-TR-42. Stanford University, December 1980.

Vinsome, P. K. W. and Westerveld, J., A Simple Method for Predicting Cap and Base Rock Heat Losees In Thermal Reservoir Simulators, J. Canadian Per. Technology. pp. 8790. July-September 1980.

Verma, A.K., Pruess, K., Tsang, C. F. and Witherspoon, P. A.. A Study of Two-Phase Concurrent Flow of Steam and Water in an Unconsolidated Porous Medium, Proceedings, 23nd National Heas Transfer Conference, Am. Society of Mechanical Engineers, pp. 135-143, Denver, CO, August 1985.
Warren, J. E and Rooh, P. J. The Behavior of Naturally Fractured Reservoirs, Sac. Pet. Engr. J., pp. 245-255, September 1963, also: Transactions, AIME, 228.

Wu, Y. S. and Pruess, K., A Muliple-Porosity Method for Simulation of Naturally Fractured Petroleum Reservoirs, SPE Reservoir Engineering, pp. 327-336, February 1988. 